\title{
Appropriate use criteria for amyloid PET imaging cannot replace guidelines: On behalf of the European Association of Nuclear Medicine
}

\author{
Jan Booij • Javier Arbizu • Jacques Darcourt • Swen Hesse • \\ Flavio Nobili • Pierre Payoux • Sabina Pappatà • Klaus Tatsch • \\ Zuzana Walker • Marco Pagani
}

Published online: 26 April 2013

(C) Springer-Verlag Berlin Heidelberg 2013

In the past 10 years, the development and evaluation of PET tracers for imaging fibrillar amyloid in the human brain in patients with Alzheimer's disease (AD) has been very successful. Brain $\beta$-amyloid plaque load is one of the "neuropathological hallmarks" of AD and has been implicated in the pathogenesis and therapy of AD. The recent approval of $\left[{ }^{18} \mathrm{~F}\right]$ florbetapir by the Food and Drug Administration (FDA) and the European Medicines Agency (EMA) in April and January 2013, respectively, for PET imaging of cerebral amyloid underlines the achievement of an important goal of molecular imaging, and emphasizes the potential role of this tool in the early diagnosis and management of patients with dementia. There are, however, some cautions concerning the use of brain amyloid radiotracers in clinical practice that have to be addressed. Therefore, the Alzheimer's Association and the Society of Nuclear Medicine and Molecular Imaging

\section{J. Booij $(\triangle)$}

Department of Nuclear Medicine, Academic Medical Center, University of Amsterdam, Amsterdam, The Netherlands

e-mail: J.Booij@amc.uva.nl

\section{J. Arbizu}

Nuclear Medicine Department, Clinica Universidad de Navarra, University of Navarra, Pamplona, Spain

\section{J. Darcourt}

Nuclear Medicine Department, Centre Antoine Lacassagne TIRO Laboratory CEA, University of Nice Sophia Antipolis, Nice, France

S. Hesse

Department of Nuclear Medicine, University of Leipzig, Leipzig, Germany

\section{F. Nobili}

Clinical Neurophysiology, Department of Neurosciences, Ophthalmology and Genetics, University of Genoa, Genoa, Italy
(SNMMI) convened the Amyloid Imaging Taskforce (AIT). The AIT recently published their guidance report in which they describe "specific use criteria" which underlines their vision of the clinical utility of amyloid PET [1]. Since we believe that amyloid imaging will be an important new tool for routine clinical studies in the near future, we resolved to provide a brief description and evaluation of this new technique and the most important topics described in the report. In addition we provide some comments on the report [1].

A hallmark study by Klunk and coworkers, published in 2004, was the first study showing that the $\left[{ }^{11} \mathrm{C}\right]$-labelled tracer termed Pittsburgh Compound-B (PiB) is able to detect amyloid deposits in patients suffering from AD [2]. Subsequently many studies have replicated this finding [3-7]. Also, a substantial number of papers on $\left[{ }^{11} \mathrm{C}\right] \mathrm{PiB}$ PET have been published in the European Journal of Nuclear Medicine and

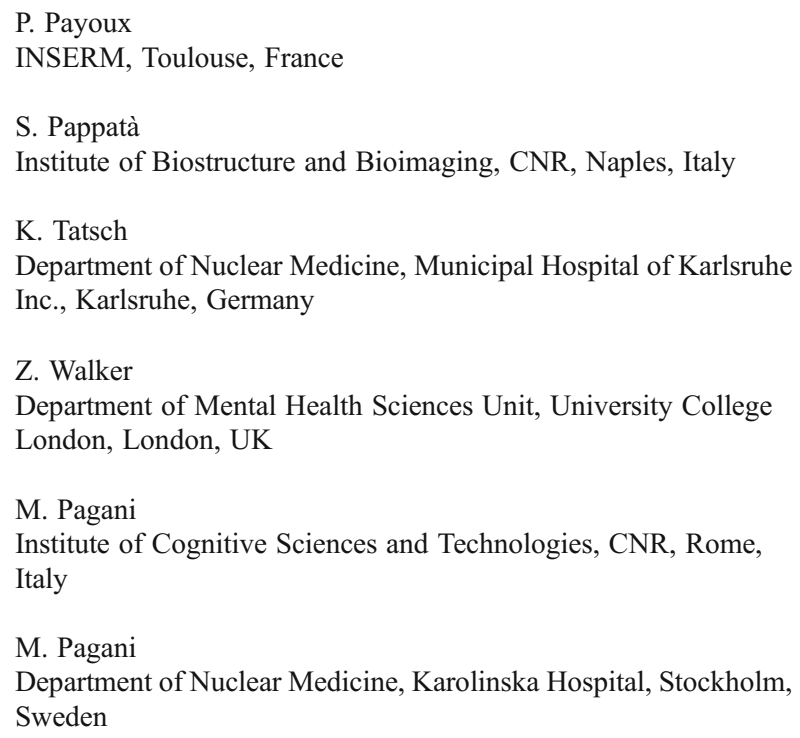


Molecular Imaging, which underscores the recognition of the importance of this topic by the Editorial Board of our Journal [8-11]. Importantly, several studies confirmed that the in vivo observations with $\left[{ }^{11} \mathrm{C}\right] \mathrm{PiB}$ PET are highly correlated with post-mortem assessment of amyloid pathology [12-14].

Due to the huge success of $\left[{ }^{11} \mathrm{C}\right] \mathrm{PiB}$ PET, the development of $\left[{ }^{18} \mathrm{~F}\right]$-labelled PET tracers for fibrillar amyloid was, for obvious reasons, a logical consequence. A couple of years after the first clinical $\left[{ }^{11} \mathrm{C}\right] \mathrm{PiB}$ PET studies were published, further investigations showed that it was also feasible to use $\left[{ }^{18} \mathrm{~F}\right]$-labelled tracers to visualize the amyloid burden in patients [15-19]. Since then several $\left[{ }^{18} \mathrm{~F}\right]$-labelled compounds have been developed, including $\left[{ }^{18} \mathrm{~F}\right] \mathrm{AV}-45$ (florbetapir), $\left[{ }^{18} \mathrm{~F}\right] 3^{\prime}-\mathrm{F}-\mathrm{PiB}$ or $\left[{ }^{18} \mathrm{~F}\right] \mathrm{GE} 067$ (flutemetamol), $\left[{ }^{18} \mathrm{~F}\right] \mathrm{AV}-1$ or $\left[{ }^{18} \mathrm{~F}\right]$ BAY94-9172 (florbetaben), and $\left[{ }^{18} \mathrm{~F}\right] A$ AD4694 or NAV4694 [15-20]. The results obtained with these novel tracers have been directly compared to those obtained with $\left[{ }^{11} \mathrm{C}\right] \mathrm{PiB}$ PET, and the specific binding of the $\left[{ }^{18} \mathrm{~F}\right]$-labelled tracers and that of $\left[{ }^{11} \mathrm{C}\right] \mathrm{PiB}$ were found to be highly and positively correlated [1]. As for $\left[{ }^{11} \mathrm{C}\right] \mathrm{PiB} \mathrm{PET}$, histopathological findings of post-mortem and biopsy material showed significant correlations with the findings of PET using $\left[{ }^{18} \mathrm{~F}\right]$ labelled tracers [21, 22].

Of particular interest is the potential contribution of PET amyloid imaging to early diagnosis of subjects at risk of developing AD. Improvement in early diagnosis could be of major relevance in the near future when specific therapeutic strategies to prevent or delay $\mathrm{AD}$ become available. In this respect great attention is given to the study of patients with mild cognitive impairment (MCI). Dementia due to neurodegenerative diseases is preceded by a period of cognitive decline not associated with significant functional impairment. This period is commonly referred to as MCI. By definition, criteria for a clinical diagnosis of dementia are not reached in these patients, although a substantial number of them are at increased risk of developing AD. However, it may be hard to predict whether an individual MCI patient will convert to dementia. Interestingly, recent studies have shown that MCI patients with amyloid PET imaging with a "positive" $\left[{ }^{11} \mathrm{C}\right] \mathrm{PiB}$ PET scan are more likely to develop AD than patients with a "negative" $\left[{ }^{11} \mathrm{C}\right] \mathrm{PiB}$ PET scan $[23,24]$. On the other hand, older asymptomatic individuals might have amyloid deposition. Estimates of age-specific positive rates for amyloid PET range from less than $5 \%$ in individuals aged 50-60 years, up to as much as 50\% in those aged 80-90 years [1]. It has been suggested that asymptomatic individuals with extensive amyloid load are at risk of developing AD [25].

Since $\left[{ }^{18} \mathrm{~F}\right]$ florbetapir has now been approved by the FDA and EMA, amyloid tracers for PET imaging will be available in many centres in the near future. For their guidance report [1], the AIT members performed an extensive search of peerreviewed publications to review the available evidence in specific clinical scenarios in which amyloid PET imaging could potentially be used. The AIT also developed a consensus of expert opinion. The AIT proposed specific "appropriate use criteria (AUC)" that define groups of patients and clinical circumstances in which amyloid PET may be helpful [1]. First, they agreed that amyloid imaging is appropriate only in individuals with: "(i) a cognitive complaint with objectively confirmed cognitive impairment; (ii) $\mathrm{AD}$ as a possible diagnosis, but when the diagnosis is uncertain after a comprehensive evaluation by a dementia expert; and (iii) when knowledge of the presence or absence of $A \beta$ pathology is expected to increase diagnostic certainty and alter management" [1]. Second, they agreed that that amyloid imaging is appropriate in the following situations: "(1) patients with persistent or progressive unexplained MCI; (2) patients satisfying core clinical criteria for possible AD because of unclear clinical presentation, either an atypical clinical course or an etiologically mixed presentation; (3) patients with progressive dementia and atypically early age of onset (usually defined as 65 years or less in age)" [1]. The AIT also agreed that amyloid imaging was inappropriate in seven situations. Examples of inappropriate indications are: (1) patients fulfilling core clinical criteria for probable AD with typical age of onset, (2) to determine dementia severity, or (3) studies in asymptomatic individuals [1].

This AIT guidance report is important and timely. The length of the list of criteria of appropriate use is, however, relatively modest, in comparison to similar lists of potential indications published in guidelines on imaging of the dopaminergic system, cerebral perfusion or $\left[{ }^{18} \mathrm{~F}\right] \mathrm{FDG}$ PET that we published on behalf of the European Association of Nuclear Medicine Neuroimaging (EANM) [26-29]. However, one should be aware of the fact that the published AIT appropriateness criteria are not a guideline. This difference is important since an imaging guideline attempts to provide a comprehensive review of the available evidence and best practice for a diagnostic procedure [30]. Nuclear medicine guidelines follow a standardized format which include AUC, but also address technical procedures, how to read images optimally, reporting of images, safety aspects, etc. [26-29, 31]. Both the SNMMI and the EANM agreed that the review process of guidelines should also be standardized [31].

The process of producing guidelines of amyloid imaging may start with taking into account the radiopharmaceutical properties of the radiopharmaceutical itself, in this situation a radiopharmaceutical that binds to fibrillar amyloid. In addition, it should consider that the clinical presentation of $\mathrm{AD}$ may be dissonant from the underlying AD pathology, in which senile plaques are one of the hallmarks [32]. This approach may allow a more appropriate coverage of the indications. In contrast to this, the AUC approach evaluates the relative benefits and risks of an imaging study for a 
specific indication to determine whether it is "reasonable" to consider performing the study. The AUC approach incorporates a "Delphi process" to generate a formal expert consensus based on the principle that input from a structured group of experts is more accurate than consensus from unstructured groups [1]. However, the quality of the results of this process depends highly on the initial questionnaire, i.e. the possible indications or non-indications list in the AIT paper. Therefore, this approach has logical limitations which may be compensated for by guidelines.

Although amyloid imaging is an important means to detect fibrillar amyloid in vivo, the health-care provider should bear in mind that a positive amyloid PET scan does not equate to a diagnosis of $\mathrm{AD}$, although it could support the clinical diagnosis. First, amyloid scans can also be "positive" in many patients suffering from dementia with Lewy bodies or amyloid angiopathy, but this is also true in a substantial percentage of older asymptomatic individuals. Furthermore, amyloid positivity does not tell us whether the complaints of the patient are caused by the amyloid plaques. So a "positive" PET scan certainly increases the likelihood that an amnestic MCI subject will develop $\mathrm{AD}$, although there is no evidence that the complaints are causally related to the amyloid deposits.

At the end of their report, the AIT touched upon a topic of particular interest to nuclear medicine physicians, that is image quality and reporting. It is obvious that training is needed for an optimal acquisition, analysis and reporting of amyloid PET images. In this regard, it is of interest that the FDA recommends training of readers and validated quantitative assessments by using tracer-specific database comparisons as an adjunct to qualitative assessments [33]. This will ensure minimal interreader variability and optimal reproducibility of quantitative results, which will be relevant for the acceptance of amyloid imaging as well.

The AIT agreed that the clinical report of amyloid images should indicate whether the scan is "amyloid-positive" or not, and the report should not confound "amyloid positivity" with AD [1]. However, this dichotomy may be an oversimplification. It has been suggested that amyloid accumulation may be present for 20 years before symptoms of dementia become apparent $[34,35]$. Consequently, in this preclinical phase, there may be considerable variation in the rate of amyloid accumulation among individuals, which may lead to an intermediate grading between a clearly "negative" scan and a "positive" scan.

In the process of establishing potential indications and nonindications based on multiple scenarios, a subcommission of the AIT had to weigh the potential clinical value of amyloid PET against the cost. We believe that it is hard, if not impossible, at this stage of the implementation of a new technique to weigh the potential clinical value of amyloid PET against the cost, simply because the cost of amyloid imaging is not yet known. For example, the results of amyloid imaging may reduce the need for other diagnostic tests $[1,36,37]$. Therefore, cost-effectiveness studies of amyloid imaging are needed. This approach may lead to a longer list of potential indications for amyloid PET in forthcoming guidelines. In this regard, we are pleased that the AIT acknowledged that the criteria for appropriate use will require periodic reassessment [1].

The AIT did not consider other proposed diagnostic biomarkers for $\mathrm{AD}$ and therefore did not draw any conclusions with regard to the relative value of amyloid PET compared with determination of cerebrospinal fluid protein levels, MRI, and $\left[{ }^{18} \mathrm{~F}\right] \mathrm{FDG}$ PET. Within the field of nuclear medicine, it is also essential to look into the position of $\left[{ }^{18} \mathrm{~F}\right]$ FDG PET versus amyloid PET. In this regard, a relevant question may be the role of amyloid imaging in a MCI or a demented patient with a typical hypometabolism pattern on a $\left[{ }^{18} \mathrm{~F}\right]$ FDG PET brain scan. Additionally, some "inappropriate" indications may change in the future. For example, when amyloid-modifying drugs become available, it may be worthwhile to examine individuals with a positive family history of dementia and/or the presence of APOE4, taking age into account as well. Also, guidelines on the use of amyloid imaging should consider how to deal with falsenegative findings, following the recent publication of some autopsy-confirmed cases of $\mathrm{AD}$ with negative amyloid scans $[14,38]$. Finally, there is also a need to cooperate with European clinical organizations (e.g. neurology, geriatrics, psychiatry) to arrive at a multidisciplinary approach to positioning amyloid tracers in guidelines, which will optimize the use of amyloid imaging in the clinic.

We are convinced that amyloid imaging will be an important new tool in routine clinical studies in the near future. We recognize the contribution of the AIT in defining the AUC, but we would like to emphasize that this work does not obviate the need for guidelines which should be written and published jointly by the EANM and the SNMMI.

\section{References}

1. Johnson KA, Minoshima S, Bohnen NI, Donohoe KJ, Foster NL, Herscovitch P, et al. Appropriate use criteria for amyloid PET: A report of the Amyloid Imaging Task Force, the Society of Nuclear Medicine and Molecular Imaging, and the Alzheimer's Association. J Nucl Med. 2013;54:476-90.

2. Klunk WE, Engler H, Nordberg A, Wang Y, Blomqvist G, Holt $\mathrm{DP}$, et al. Imaging brain amyloid in Alzheimer's disease with Pittsburgh Compound-B. Ann Neurol. 2004;55:306-19.

3. Kemppainen NM, Aalto S, Wilson IA, Någren K, Helin S, Brück A, et al. Voxel-based analysis of PET amyloid ligand [11C]PIB uptake in Alzheimer disease. Neurology. 2006;67:1575-80.

4. Edison P, Archer HA, Hinz R, Hammers A, Pavese N, Tai YF, et al. Amyloid, hypometabolism, and cognition in Alzheimer disease: an [11C]PIB and [18F]FDG PET study. Neurology. 2007;68:501-8.

5. Edison P, Rowe CC, Rinne JO, Ng S, Ahmed I, Kemppainen N, et al. Amyloid load in Parkinson's disease dementia and Lewy body 
dementia measured with [11C]PIB positron emission tomography. J Neurol Neurosurg Psychiatry. 2008;79:1331-8.

6. Gomperts SN, Rentz DM, Moran E, Becker JA, Locascio JJ, Klunk WE, et al. Imaging amyloid deposition in Lewy body diseases. Neurology. 2008;71:903-10.

7. Chételat G, Villemagne VL, Bourgeat P, Pike KE, Jones G, Ames $\mathrm{D}$, et al. Relationship between atrophy and beta-amyloid deposition in Alzheimer disease. Ann Neurol. 2010;67:317-24.

8. Santillo AF, Gambini JP, Lannfelt L, Långström B, Ulla-Marja L, Kilander L, et al. In vivo imaging of astrocytosis in Alzheimer's disease: an 11C-L-deuteriodeprenyl and PIB PET study. Eur J Nucl Med Mol Imaging. 2011;38:2202-8.

9. Nordberg A, Carter SF, Rinne J, Drzezga A, Brooks DJ, Vandenberghe R, et al. A European multicentre PET study of fibrillar amyloid in Alzheimer's disease. Eur J Nucl Med Mol Imaging. 2013;40:104-14.

10. Tolboom N, Yaqub M, Boellaard R, Luurtsema G, Windhorst AD, Scheltens $\mathrm{P}$, et al. Test-retest variability of quantitative [11C]PIB studies in Alzheimer's disease. Eur J Nucl Med Mol Imaging. 2009;36:1629-38.

11. Engler H, Santillo AF, Wang SX, Lindau M, Savitcheva I, Nordberg A, et al. In vivo amyloid imaging with PET in frontotemporal dementia. Eur J Nucl Med Mol Imaging. 2008;35:100-6.

12. Bacskai BJ, Frosch MP, Freeman SH, Raymond SB, Augustinack JC, Johnson KA, et al. Molecular imaging with Pittsburgh Compound B confirmed at autopsy: a case report. Arch Neurol. 2007;64:431-4.

13. Ikonomovic MD, Klunk WE, Abrahamson EE, Mathis CA, Price JC, Tsopelas ND, et al. Post-mortem correlates of in vivo PiB-PET amyloid imaging in a typical case of Alzheimer's disease. Brain. 2008;131:1630-45.

14. Ikonomovic MD, Abrahamson EE, Price JC, Hamilton RL, Mathis CA, Paljug WR, et al. Early AD pathology in a [C-11]PiB-negative case: a PiB-amyloid imaging, biochemical, and immunohistochemical study. Acta Neuropathol. 2012;123:433-47.

15. Rowe CC, Ackerman U, Browne W, Mulligan R, Pike KL, O'Keefe $G$, et al. Imaging of amyloid $\beta$ in Alzheimer's disease with 18F-BAY94-9172, a novel PET tracer: proof of mechanism. Lancet Neurol. 2008;7:129-35.

16. Koole M, Lewis DM, Buckley C, Nelissen N, Vandenbulcke M, Brooks DJ, et al. Whole-body biodistribution and radiation dosimetry of 18F-GE067: a radioligand for in vivo brain amyloid imaging. J Nucl Med. 2009;50:818-22.

17. Wong DF, Rosenberg PB, Zhou Y, Kumar A, Raymont V, Ravert HT, et al. In vivo imaging of amyloid deposition in Alzheimer disease using the radioligand 18F-AV-45 (florbetapir F 18). J Nucl Med. 2010;51:913-20.

18. Clark CM, Schneider JA, Bedell BJ, Beach TG, Bilker WB, Mintun MA, et al. Use of florbetapir-PET for imaging betaamyloid pathology. JAMA. 2011;305:275-83.

19. Barthel H, Gertz HJ, Dresel S, Peters O, Bartenstein P, Buerger K, et al. Cerebral amyloid- $\beta$ PET with florbetaben $(18 \mathrm{~F})$ in patients with Alzheimer's disease and healthy controls: a multicentre phase 2 diagnostic study. Lancet Neurol. 2011;10:424-35.

20. Cselényi Z, Jönhagen ME, Forsberg A, Halldin C, Julin P, Schou $\mathrm{M}$, et al. Clinical validation of 18F-AZD4694, an amyloid- $\beta$ specific PET radioligand. J Nucl Med. 2012;53:415-24.

21. Clark CM, Pontecorvo MJ, Beach TG, Bedell BJ, Coleman RE, Doraiswamy PM, et al. Cerebral PET with florbetapir compared with neuropathology at autopsy for detection of neuritic amyloid- $\beta$ plaques: A prospective cohort study. Lancet Neurol. 2012;11:669-78.

22. Rinne JO, Wong DF, Wolk DA, Leinonen V, Arnold SE, Buckley C, et al. $[18 \mathrm{~F}]$ Flutemetamol PET imaging and cortical biopsy histopathology for fibrillar amyloid $\beta$ detection in living subjects with normal pressure hydrocephalus: pooled analysis of four studies. Acta Neuropathol. 2012;124:833-45.

23. Okello A, Koivunen J, Edison P, Archer HA, Turkheimer FE, Någren $\mathrm{K}$, et al. Conversion of amyloid positive and negative MCI to AD over 3 years: an 11C-PIB PET study. Neurology. 2009:73:754-60.

24. Koivunen J, Scheinin N, Virta JR, Aalto S, Vahlberg T, Någren K, et al. Amyloid PET imaging in patients with mild cognitive impairment: a 2-year follow-up study. Neurology. 2011;76:1085-90.

25. Morris JC, Price JL. Pathologic correlates of nondemented aging, mild cognitive impairment, and early-stage Alzheimer's disease. J Mol Neurosci. 2001;17:101-18.

26. Varrone A, Asenbaum S, Vander Borght T, Booij J, Nobili F, Någren $\mathrm{K}$, et al. EANM procedure guidelines for PET brain imaging using [18F]FDG, version 2. Eur J Nucl Med Mol Imaging. 2009;36:2103-10.

27. Kapucu OL, Nobili F, Varrone A, Booij J, Vander Borght T, Någren $\mathrm{K}$, et al. EANM procedure guideline for brain perfusion SPECT using 99mTc-labelled radiopharmaceuticals, version 2. Eur J Nucl Med Mol Imaging. 2009;36:2093-102.

28. Van Laere K, Varrone A, Booij J, Vander Borght T, Nobili F, Kapucu OL, et al. EANM procedure guidelines for brain neurotransmission SPECT/PET using dopamine D2 receptor ligands, version 2. Eur J Nucl Med Mol Imaging. 2010;37:434-42.

29. Darcourt J, Booij J, Tatsch K, Varrone A, Vander Borght T, Kapucu OL, et al. EANM procedure guidelines for brain neurotransmission SPECT using 123I-labelled dopamine transporter ligands, version 2. Eur J Nucl Med Mol Imaging. 2010;37:443-50.

30. Patel MR, Spertus JA, Brindis RG, Hendel RC, Douglas PS, Peterson ED, et al. ACCF proposed method for evaluating the appropriateness of cardiovascular imaging. J Am Coll Cardiol. 2005;46:1606-13.

31. Delbeke D, Chiti A, Christian P, Darcourt J, Donohoe K, Flotats A, et al. SNMMI/EANM guideline for guideline development 6.0. J Nucl Med Technol. 2012;40:283-9.

32. Dubois B, Feldman HH, Jacova C, Cummings JL, Dekosky ST, Barberger-Gateau P, et al. Revising the definition of Alzheimer's disease: a new lexicon. Lancet Neurol. 2010;9:1118-27.

33. Food and Drug Administration. Advisory Committee Briefing Document. New Drug Application 202-008: Amyvid (florbetapir F 18 injection). Available from: http://www.fda.gov/downloads/ AdvisoryCommittees/CommitteesMeetingMaterials/Drugs/ PeripheralandCentralNervousSystemDrugsAdvisoryCommittee/ UCM240265.pdf.

34. Fleisher AS, Chen K, Quiroz YT, Jakimovich LJ, Gomez MG, Langois $C M$, et al. Florbetapir PET analysis of amyloid- $\beta$ deposition in the presenilin 1 E280A autosomal dominant Alzheimer's disease kindred: a cross-sectional study. Lancet Neurol. 2012;11:1057-65.

35. Villemagne VL, Pike KE, Chételat G, Ellis KA, Mulligan RS, Bourgeat $P$, et al. Longitudinal assessment of $A \beta$ and cognition in aging and Alzheimer disease. Ann Neurol. 2011;69:181-92.

36. Ossenkoppele R, Prins ND, Pijnenburg YA, Lemstra AW, van der Flier WM, Adriaanse SF, et al., Impact of molecular imaging on the diagnostic process in a memory clinic. Alzheimers Dement. 2012 . doi:10.1016/j.jalz.2012.07.003.

37. Grundman M, Pontecorvo MJ, Salloway SP, Doraiswamy PM, Fleisher AS, Sadowsky CH, et al. Potential impact of amyloid imaging on diagnosis and intended management in patients with progressive cognitive decline. Alzheimer Dis Assoc Disord. 2013;27:4-15.

38. Chételat G. Alzheimer disease: $A \beta$-independent processesrethinking preclinical AD. Nat Rev Neurol. 2013. doi:10.1038/ nrneurol.2013.21. 